\title{
Fucus vesiculosus and spiralis species complex: a nested model of local adaptation at the shore level
}

\author{
Emmanuelle Billard ${ }^{1,2,3,4}$, Ester Serrão ${ }^{3}$, Gareth Pearson $^{3}$, Christophe Destombe ${ }^{1,2}$, \\ Myriam Valero ${ }^{1,2, *}$
}

\author{
${ }^{1}$ Université Pierre et Marie Curie (UPMC) Station Biologique de Roscoff, Equipe Biologie Evolutive et Diversité Marine \\ (BEDIM), UMR 7144, BP 74, 29682 Roscoff Cedex, France \\ ${ }^{2}$ Centre National de la Recherche Scientifique (CNRS) Station Biologique de Roscoff, Equipe Biologie Evolutive et Diversité \\ Marine (BEDIM), UMR 7144, BP 74, 29682 Roscoff Cedex, France \\ ${ }^{3}$ Centro Ciências do Mar (CCMAR), Centro Interdisciplinar de Investigaçao Marinha e Ambiental (CIMAR), Universidade do \\ Algarve, Gambelas, 8005-139 Faro, Portugal \\ ${ }^{4}$ Present address: Laboratoire Génétique et Evolution des Populations Végétales (GEPV), Université Lille 1, UMR 8016, \\ 59655 Villeneuve d'Ascq Cedex, France
}

\begin{abstract}
Intertidal rocky shores provide classic examples of habitat-driven divergent selection. We show that the species complex Fucus vesiculosus L./F. spiralis L. is composed of 3 distinct genetic entities that have evolved along different time scales. Using assignment tests based on microsatellite markers and performed on randomly sampled individuals in 2 separate geographic regions (Portugal and France), we reveal that F. spiralis consists of 2 genetic entities that have distinct vertical distributional patterns along the intertidal gradient of selective pressures. Individuals assigned to the cluster found higher on the shore are also morphologically different. They are smaller and bushy, with dichotomous ramifications and no sterile rime around receptacles. Patterns of genetic divergence suggest different times and pathways to reproductive isolation. Divergence between F. vesiculosus and the $F$. spiralis complex seems to have occurred first, coinciding with divergence in reproductive mode; dioecy versus selfing hermaphroditism. Later, in the hermaphroditic lineage, parallel evolution of 2 co-occurring genetic clusters may have been driven by natural selection and facilitated by high selfing rates in the F. spiralis complex.
\end{abstract}

KEY WORDS: Environmental gradient - Speciation $\cdot$ Fucus spp. · Gene flow · Genetic cluster

\section{INTRODUCTION}

The process of divergence by which new species originate was traditionally thought to occur without gene flow between geographically isolated populations (i.e. allopatric speciation). However, a number of theoretical models and examples of speciation in the face of gene flow have now emerged (for recent reviews see Schluter, 2001, 2009, Hey, 2006, Butlin et al. 2008, Fitzpatrick et al. 2008). Sympatric speciation driven by disruptive selection while populations are still exchanging genes, also referred to as 'adaptive speciation,' is now considered a possible mechanism of speciation, where the evolution of reproductive isolation is a response to selection and not a simple byproduct of divergence.

Intertidal rocky shores, with their sharp gradients of physical and biotic selective pressures, have provided some of the most classic examples of habitat-driven divergence with gene flow, a first step towards broad sympatric speciation. Such is the case of the high/low shore ecotypes of the gastropod Littorina saxatilis, which can mate and yield fertile intermediates (RolánAlvarez et al. 1997), a divergent selection process that has apparently occurred independently in different intertidal shores of northern Spain (Quesada et al. 
2007, Galindo et al. 2009, but see Butlin et al. 2008). The intertidal zone offers highly heterogeneous habitats over very small scales, where, based on the local emersion times, organisms may encounter contrasting levels of selective pressure. Stressors may be abiotic, such as desiccation and wave exposure, or they can be biotic, such as the presence of predators or competitors. The combination of these different factors strongly shapes species distribution along intertidal environmental gradients, as testified by the local distributions of intertidal organisms, which have been an important object of study for over a century (Jonsson et al. 2006). Among these, the genus Fucus is composed by multiple species that are distributed within different but overlapping vertical limits all along northern Atlantic intertidal zones, from the mediolittoral (F. serratus, $F$. evanescens) to the upper shore (F. spiralis). One of the earliest hypotheses explaining this pattern was that biotic factors are more often involved in determining lower shore limits, whereas abiotic stressors such as desiccation are the major factors delimiting the upper limit of species (Connell 1972, Underwood 1979, Lubchenco 1980), although alternative explanations and more complex interactions are currently known in intertidal organisms (e.g. Hawkins \& Hartnoll 1985).

Evolutionary divergence between Fucus populations and species can take place rapidly in response to physical stress, as documented for emersion stress (Pearson et al. 2000) and temperature (Pearson et al. 2009). In Fucus species co-occurring along intertidal gradients, upper-shore $F$. spiralis recovers better from desiccation (Dring \& Brown 1982) and from exposure to more extreme high and low temperatures (Chapman 1995, Davison \& Pearson 1996) than F. vesiculosus or F. serratus, and, in turn, F. vesiculosus recovers better from temperature stress than lower-shore $F$. serratus, although in the latter the recovery capacity is even further diminished at the warmer edge of the distributional range (Pearson et al. 2009). Species from the upper shore also tend to have greater physiological performance at low tide while still hydrated (Skene 2004). Field studies also suggest that distributional limits may be determined by competitive interactions mediated by emersion stress. For example, F. vesiculosus can extend its vertical range upshore when F. spiralis is removed (Hawkins \& Hartnoll 1985, Chapman \& Johnson 1990), whereas F. spiralis is outcompeted by F. vesiculosus in the mid-shore (Chapman 1990, 1995). Moreover, Vernet \& Harper (1980) advanced the hypothesis that the contrasting selective pressures on the shore could be the driving force promoting divergence in mating systems between F. spiralis (hermaphroditic) and $F$. vesiculosus (dioecious). Typically, for the Fucus species complex, vertical gradients coincide with variation in the reproductive system, with her- maphroditic F. spiralis found on average above dioecious $F$. vesiculosus. Reproductive strategies are thus also suspected to be involved in the maintenance of different species along this environmental gradient. Hermaphroditism by enabling selfing, in addition to limiting gene flow between species, allows the maintenance of local adaptations (see Takebayashi \& Morrell 2001 for a review). This may be important for the persistence of the high intertidal species $F$. spiralis, and data available to date suggest that selfing is predominant in this species (e.g. Billard et al. 2005, Engel et al. 2005, Perrin et al. 2007, but see also Coleman \& Brawley 2005).

Fucus species are genetically very closely related, and all phylogenetic studies (Leclerc et al. 1998, Serrão et al. 1999, Coyer et al. 2006) suggest a recent and rapid radiation. The genus Fucus consists of 2 clades, the first containing $F$. vesiculosus and $F$. spiralis, and a second that includes $F$. serratus, which are the dominant Fucus species found on open-coast rocky shores of the European eastern Atlantic. Fucus species are still capable of hybridization (Stomps 1911, Kniep 1925, Coyer et al. 2002, 2007, Wallace et al. 2004, Billard et al. 2005, Engel et al. 2005) suggesting firstly that their separation is recent and that where they cooccur on the same shores, environmental gradients may play an important role in the maintenance of species. In addition, several morphotypes have been described, of which several varieties are still currently accepted (cf. www.algaebase.org, Guiry \& Guiry 2009), including several in $F$. vesiculosus but only one in F. spiralis: F. spiralis var. platycarpus Batters 1902 (cited in Gomez-Garreta 2000). It is not understood whether such varieties are of phenotypic or genotypic nature and whether they are strictly sympatric or habitat-segregated to any extent when occurring on the same shore.

Distribution along a linear gradient thus offers a unique opportunity to study micro-evolutionary mechanisms. The present study aims at understanding the spatial distribution of Fucus genetic entities along intertidal emersion stress gradients and the possible pathway having led to the evolution of these Fucus entities.

\section{MATERIALS AND METHODS}

Transect sampling. Sampling of individuals was conducted in Santec (Brittany, France; $48^{\circ} 42^{\prime} 80^{\prime \prime} \mathrm{N}$, $04^{\circ} 02^{\prime} 21^{\prime \prime} \mathrm{W}$ ) and in Viana do Castelo (north Portugal; $\left.41^{\circ} 41^{\prime} 51^{\prime \prime} \mathrm{N}, 8^{\circ} 51^{\prime} 07^{\prime \prime} \mathrm{W}\right)$. These 2 sites are rocky shores moderately exposed to wave activity, showing different topography and tide amplitude (Fig. 1). In Santec, the rocky shore is subject to transient sand 

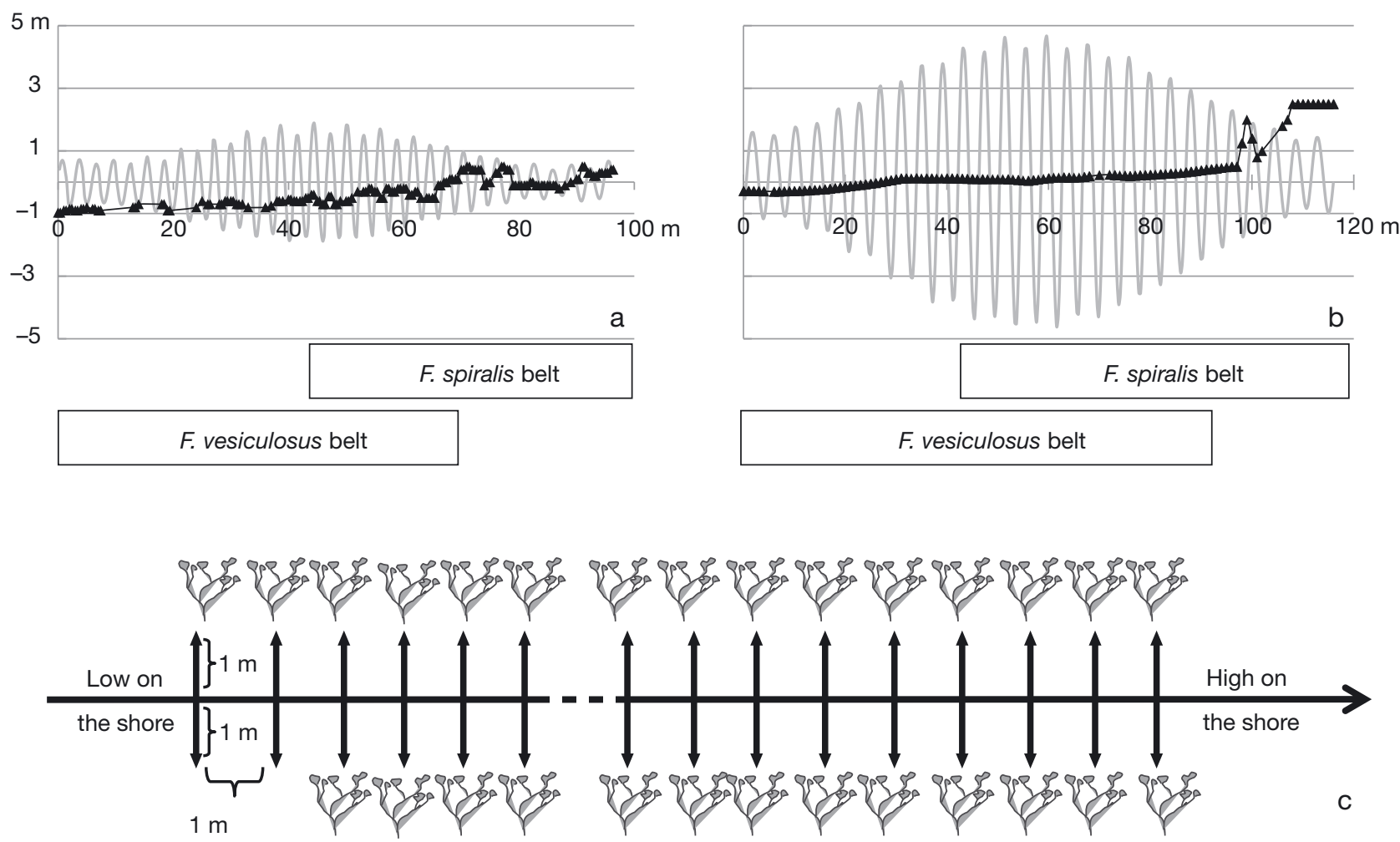

Fig. 1. Profiles of transects (in black) in (a) Viana, Portugal (tidal amplitude $\approx 4 \mathrm{~m}$ ) and (b) Santec, France (tidal amplitude $\approx 10 \mathrm{~m}$ ). Tidal phase and amplitude (in grey) were calculated for the nearby locations of Vigo and Roscoff, respectively, with the SHOM Web site (www.shom.fr). To determine the transect positions in relation to the mid-tide point, we noted, for at least 2 distinct points of the transects, the time at which they were reached by the rising tide. (c) Sampling design: along a transect from low to high shore, 2 individuals of the Fucus genus were taken at $1 \mathrm{~m}$ to the left and $1 \mathrm{~m}$ to the right, at every meter along the transect, without selection of morphotype or species

cover with the presence of small rolling stones, while in Viana, the shore is mainly composed of bedrock. The less stable topography in Santec may explain the higher intermixing of species along the intertidal succession in comparison with Viana. Individuals were sampled along a vertical transect (Fig. 1a,b) from the lower limit of Fucus vesiculosus belt to the higher limit of F. spiralis belt, by collecting 2 individuals of Fucus spp. (no a priori species or morphotype selection in order to avoid subjective biases) at every meter along the transect: one at $1 \mathrm{~m}$ to the left and one at $1 \mathrm{~m}$ to the right (Fig. 1c). Transects were sampled in 2005 in Portugal $(\mathrm{l}=83 \mathrm{~m}, \mathrm{n}=162)$ and in 2006 in France $(\mathrm{l}=$ $106 \mathrm{~m}, \mathrm{n}=199$ ). Vegetative tips (2 to 3 for each ind.) were stored in silica crystals for molecular analyses, and at least 2 receptacles (fertile zones) per individual were taken to determine the sexual phenotype. The elevation of the transect was determined by taking the hour of immersion of at least 2 distinct points. At Santec, shore height was determined every $5 \mathrm{~m}$ with a clinometer. In addition, relative heights of individuals sampled on rocks were measured. On the rocky shore of Viana, all individual relative heights were noted.
Finally, the median height of each taxon was calculated in order to define the mean emersion time during the year (based on the SHOM database [www.shom.fr] for Roscoff and Vigo, the closest station $60 \mathrm{~km}$ north from Viana for which information was available in the SHOM database in 2006).

DNA extraction, PCR reaction and genotyping. DNA for genotyping was extracted from ca. $4 \mathrm{mg}$ of dried tissue using the Nucleospin ${ }^{\circledR}$ Multi-96 plant kit (Macherey-Nagel) according to the manufacturer's protocol and diluted 1:250. Polymerase chain reactions (PCR) on a MJ Research PTC200 thermocycler and electrophoresis of PCR products on a automated DNA sequencer (Li-Cor 4200) were performed for the 7 microsatellite loci L20, L38, L94, L58, L78, and fsp1, fsp2, as described, respectively, in Engel et al. (2003) and Perrin et al. (2007).

Genetic analyses. Estimations of occurrence and frequency of null alleles (Fll) were performed using Micro-checker (Van Oosterhout et al. 2004, 2006) and based on the algorithm of Van Oosterhout et al. (2006). Population genetics parameters were estimated using Genetix software (Belkhir et al. 2004) and Fstat 
(Goudet 1995). Assignment of individuals to species and detection of hybrids was performed with a modelbased genetic admixture analysis implemented in Structure software (Pritchard et al. 2000). This software uses a Bayesian method to identify clusters of genetically similar individuals based on their multilocus genotypes by creating groups within which HardyWeinberg and linkage disequilibrium are minimized. Individuals are assigned to $K$ different clusters (populations); it creates and detects admixed individuals, possibly resulting from recent hybridization and/or introgression of these clusters. Since inbreeding and selfing may induce linkage disequilibrium among loci and Hardy-Weinberg disequilibrium, which may not be suitable for assignment tests, analyses were also performed with InStruct (Gao et al. 2007), which takes into account the possibility of selfing, and results from both were compared. Analyses were run assuming different numbers of parental populations from $K=2$ to $K=5$, with 10 iterations for each assumed K. A burn-in of 100000 repetitions and a run length of 1000000 were used. To avoid potentially confounding geographic structure, analyses of transects were carried out separately for each region and year. Individuals were then assigned to each cluster according to $q_{t i}$ the proportion of individual genome assigned to each taxon. An individual was considered to be a hybrid when $q_{2 i}$ (the proportion of genome assigned to the second taxon) $\geq 0.1$. Due to the presence of Fucus serratus in the French transect, these individuals were taken into account for the assignment of individuals from France to clusters, but not in the latter analyses.

After removal of genetically intermediate individuals from the analysis we calculated for each cluster in each region the mean number of alleles, the averaged observed heterozygosity $\left(H_{o}\right)$ and the average nonbiased expected heterozygosity $\left(H_{e}\right)$ using the Fstat software (Goudet 1995). Allele frequencies were visualized with the R-package MsatAllele_1.0 (Alberto 2009). $F_{\mathrm{ST}}$ were calculated between all pairs of populations using Genetix software (Belkhir et al. 2004). Four levels of comparison were thus considered: intraspecific and intraregional, intraspecific and interregional, interspecific and intraregional, and interspecific and interregional. These data were summarized and statistically tested with a principal component analysis (PCA) were performed using PCA-GEN software (version 1.2; Goudet 1999). The statistical significance associated with each axis was calculated over 1000 randomizations. All individuals with missing data at one or more loci were excluded. To analyze the mating system, fixation indices ( $F_{I S}$ Weir \& Cockerham 1984) were calculated over all loci and for each locus within each population using Fstat software version 1.2 (Goudet 1995). Heterozygote deficiencies and excess were tested using 10000 permutations of alleles among individuals within each population. Selfing rates among populations were also inferred with InStruct via a model detailed in Gao et al. (2007) and by a multilocus method implemented in the RMES software of David et al. (2007).

\section{RESULTS}

\section{Genotyping}

Individual genotypes were determined at 7 microsatellite loci in 361 individuals, of which 24 individuals were excluded from the analysis because amplification failed for at least one locus. All 7 loci showed substantial variability with 9 to 16 alleles per locus and a mean Ho ranging from 0.19 to 0.26 in France and from 0.09 to 0.23 in Portugal, depending on the locus (data not shown). Null alleles were detected for 2 loci (L20 and fsp2) and occasionally for fsp1 (Table 1), with Fll varying from 0.07 to 0.29 , although these estimations may be biased (overestimated) because of the high inbreeding rate in Fucus spiralis.

\section{Cluster analysis}

Assigning individuals to genetic clusters according to their multilocus genotype without a priori indication of the number of clusters $(K)$ or individual species identity revealed clusters that appear to correspond to the species known to occur in the area, Fucus spiralis, $F$. vesiculosus, and, in France, also F. serratus. However, contrary to our expectation, F. spiralis was divided into 2 distinct genetic clusters in structure analyses resulting in higher probabilities for values of $K$ that consider 2 clusters for $F$. spiralis ( $K=3$ in Portugal and $K=4$ in France, where the species $F$. serratus was also sampled). Since a high rate of selfing is suspected in F. spiralis, individual assignment was also performed with InStruct, which eliminates the assumption of Hardy-Weinberg equilibrium within clusters. Since assignment of individuals was consistent between both methods, only InStruct results are shown in Fig. 2.

Individuals were classified into 3 (Portugal) or 4 (France) distinct genetic clusters, and they were considered as intermediate when at least $10 \%$ of their genome was assigned to a second cluster. For the sample from Portugal, 78 individuals were assigned to Fucus vesiculosus, 30 to the first cluster of $F$. spiralis, 19 to the second cluster of $F$. spiralis, and 20 individuals were classified as intermediates, 15 between $F$. vesiculosus and the first cluster of $F$. spiralis and 5 between $F$. vesiculosus and the second cluster of $F$. spiralis 
Table 1. Summary of genetic diversity within identified clusters. $H_{e}$ : non-biased expected heterozygosity; $H_{o}$ : observed heterozygosity, $F_{I S}$ and frequency (Fll) of null allele per locus and population. Significant values $(\mathrm{p}<0.05)$ are indicated in bold, -: not possible to calculate $F_{I S} . H_{e}$ and $H_{o}$ averaged over loci are given for each genetic cluster

\begin{tabular}{|c|c|c|c|c|c|c|c|c|c|c|}
\hline Cluster & Region & $\mathrm{n}$ & & L20 & L38 & L58 & L78 & L94 & Fsp1 & Fsp2 \\
\hline \multirow[t]{8}{*}{ Fucus vesiculosus } & Portugal & 78 & $H_{e}$ & 0.37 & 0.64 & 0.38 & 0.67 & 0.59 & 0.70 & 0.58 \\
\hline & & & $H_{o}$ & 0.24 & 0.54 & 0.46 & 0.67 & 0.56 & 0.69 & 0.21 \\
\hline & & & Fll & 0.13 & 0.08 & 0.00 & 0.00 & 0.00 & 0.00 & 0.29 \\
\hline & & & $F_{I S}$ & 0.35 & 0.15 & -0.23 & 0.01 & 0.05 & 0.02 & 0.65 \\
\hline & France & 84 & $H_{e}$ & 0.85 & 0.78 & 0.71 & 0.80 & 0.60 & 0.84 & 0.65 \\
\hline & & & $H_{o}$ & 0.74 & 0.77 & 0.63 & 0.84 & 0.57 & 0.79 & 0.56 \\
\hline & & & Fll & 0.07 & 0.00 & 0.00 & 0.00 & 0.00 & 0.00 & 0.08 \\
\hline & & & $F_{I S}$ & 0.13 & 0.01 & 0.13 & -0.05 & 0.04 & 0.06 & 0.14 \\
\hline \multirow[t]{8}{*}{ F. spiralis-Low } & Portugal & 30 & $H_{e}$ & 0.00 & 0.03 & 0.00 & 0.22 & 0.07 & 0.03 & 0.10 \\
\hline & & & $H_{o}$ & 0.00 & 0.03 & 0.00 & 0.13 & 0.03 & 0.03 & 0.03 \\
\hline & & & Fll & 0.00 & 0.00 & 0.00 & 0.00 & 0.00 & 0.00 & 0.18 \\
\hline & & & $F_{I S}$ & - & - & - & 0.39 & 0.50 & - & 0.66 \\
\hline & France & 50 & $H_{e}$ & 0.04 & 0.00 & 0.02 & 0.00 & 0.04 & 0.28 & 0.00 \\
\hline & & & $H_{o}$ & 0.00 & 0.00 & 0.02 & 0.00 & 0.00 & 0.02 & 0.00 \\
\hline & & & Fll & 0.00 & 0.00 & 0.00 & 0.00 & 0.00 & 0.31 & 0.00 \\
\hline & & & $F_{I S}$ & 1.00 & - & - & - & 1.00 & 0.92 & - \\
\hline \multirow[t]{8}{*}{ F. spiralis-High } & Portugal & 19 & $H_{e}$ & 0.00 & 0.10 & 0.00 & 0.10 & 0.05 & 0.10 & 0.05 \\
\hline & & & Ho & 0.00 & 0.05 & 0.00 & 0.05 & 0.05 & 0.11 & 0.05 \\
\hline & & & Fll & 0.00 & 0.00 & 0.00 & 0.00 & 0.00 & 0.00 & 0.00 \\
\hline & & & $F_{I S}$ & - & 0.50 & - & 0.50 & - & -0.01 & - \\
\hline & France & 19 & $H_{e}$ & 0.00 & 0.00 & 0.00 & 0.00 & 0.00 & 0.00 & 0.51 \\
\hline & & & $H_{o}$ & 0.00 & 0.00 & 0.00 & 0.00 & 0.00 & 0.00 & 0.26 \\
\hline & & & Fll & 0.00 & 0.00 & 0.00 & 0.00 & 0.00 & 0.00 & 0.21 \\
\hline & & & $F_{I S}$ & - & - & - & - & - & - & 0.49 \\
\hline
\end{tabular}

(Fig. 2). Selfing rates, inferred with InStruct and RMES, were consistent between methods and were, respectively, 0.8 and 0.9 for the first cluster of $F$. spiralis and 0.8 and 0.9 for the second cluster. For the sample from France, individuals were assigned as $84 \mathrm{~F}$. vesiculosus, 50 to the first cluster of $F$. spiralis, 19 to the second cluster of F. spiralis, 17 to F. serratus, and 20 intermediates, 6 between $F$. vesiculosus and the first cluster of $F$. spiralis, 4 between $F$. vesiculosus and the second cluster of $F$. spiralis, 8 between $F$. vesiculosus and $F$. serratus and 2 between $F$. serratus and F. spiralis (Fig. 2). In this case, estimation of selfing rate was not possible due to the lack of polymorphism for the 2 F. spiralis clusters. Given that F. serratus was not present in the transect of Portugal, the remaining analyses will discuss mainly the other clusters identified.

Allelic diversity was always greater in Fucus vesiculosus than in F. spiralis, whatever the locus considered (Table 1, Fig. 3). Among the 77 alleles recorded over the 7 loci and the 3 different clusters, the majority (75) were retrieved within $F$. vesiculosus, whereas only 14 were observed in the first cluster of $F$. spiralis and even fewer (10) in the second (Fig. 3). Many alleles (54) were thus diagnostic of $F$. vesiculosus because they were never observed in the F. spiralis clusters. In contrast, only one allele (allele 157 at locus L94) was diagnostic of the first cluster of $F$. spiralis and only one allele (allele 198, locus Fsp2) was diagnostic of the second.
Two loci (L20 and L78) were diagnostic between the 2 clusters of F. spiralis. Two loci (L38 and L58) were fixed for the same allele in all F. spiralis populations, and the 3 remaining loci allowed differentiation between Portugal and France within clusters (Fig. 3). The PCA summarizes the information given by the 7 loci (Fig. 4) and indicates a clear distinction between the 3 clusters, regardless of the regional origin of the populations. Indeed, the global $F_{S T}(0.4)$ is highly significant ( $p=$ 0.001 ) with 2 significant axes according to the brokenstick. The first axis, containing $56 \%$ of the total inertia, segregates $F$. vesiculosus from the $2 F$. spiralis clusters and the second axis, which explains $24 \%$ of the total inertia, segregates the 2 clusters of F. spiralis. Indeed, concerning $F$. vesiculosus, $F_{S T}$ between clusters ranged from 0.40 to 0.56 , while it only reached 0.14 within cluster-among regions. On the other hand, $F_{S T}$ between clusters of F. spiralis were much higher (0.83 to 0.90), but were also high within clusters-among regions (0.80 for F. spiralis-Low and 0.43 for F. spiralisHigh). All $F_{S T}$ values were highly significant.

\section{Cluster distribution along the vertical shore gradient}

The median height of the 3 clusters on the shore is clearly different (Fig. 5). In the transect sampled in Portugal, there is a clear gradient in the distribution of the 
3 clusters, with Fucus vesiculosus occurring lower on the shore, the first cluster of F. spiralis (F. spiralis-Low) occupying the middle part of the shore, and the second cluster of F. spiralis (F. spiralis-High) the higher part. In the transect from France, the situation is more complex, as F. spiralis-Low was found mostly admixed with $F$. vesiculosus, while there was no overlap in the distribution of the 2 types of $F$. spiralis. Since differences in
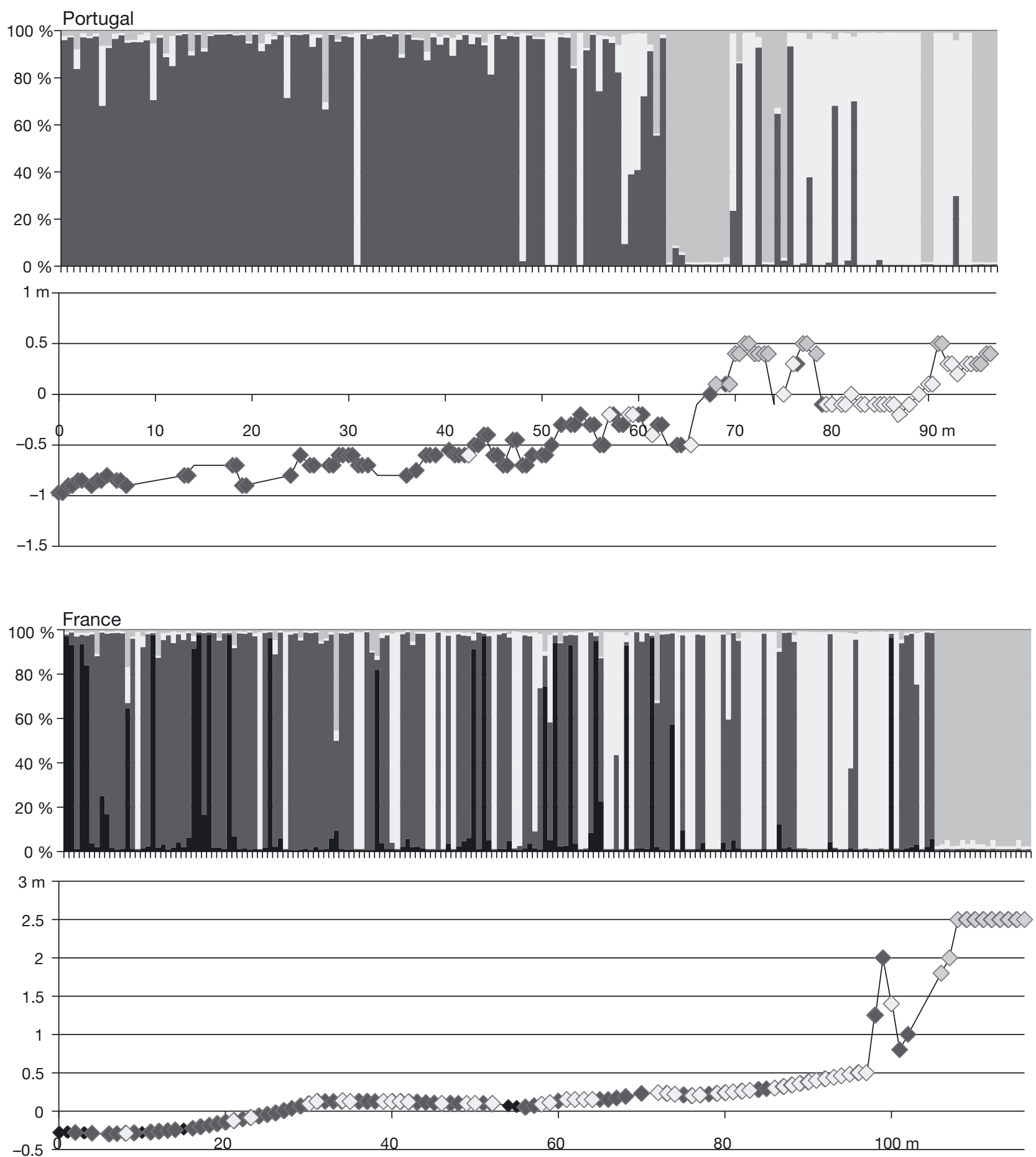

Fig. 2. Bayesian analysis with InStruct software for the different transects. Each vertical bar represents a different individual. Each shade represents $q_{t i}$ the proportion of individual genome assigned to each taxon; from black to lightest grey: Fucus serratus, F. vesiculosus, F. spiralis-High, and F. spiralis-Low. Individuals are ordered from the lower to the upper shelf. Under each Bayesian analysis output figure, the partitioning of each cluster is represented on the transect profile 

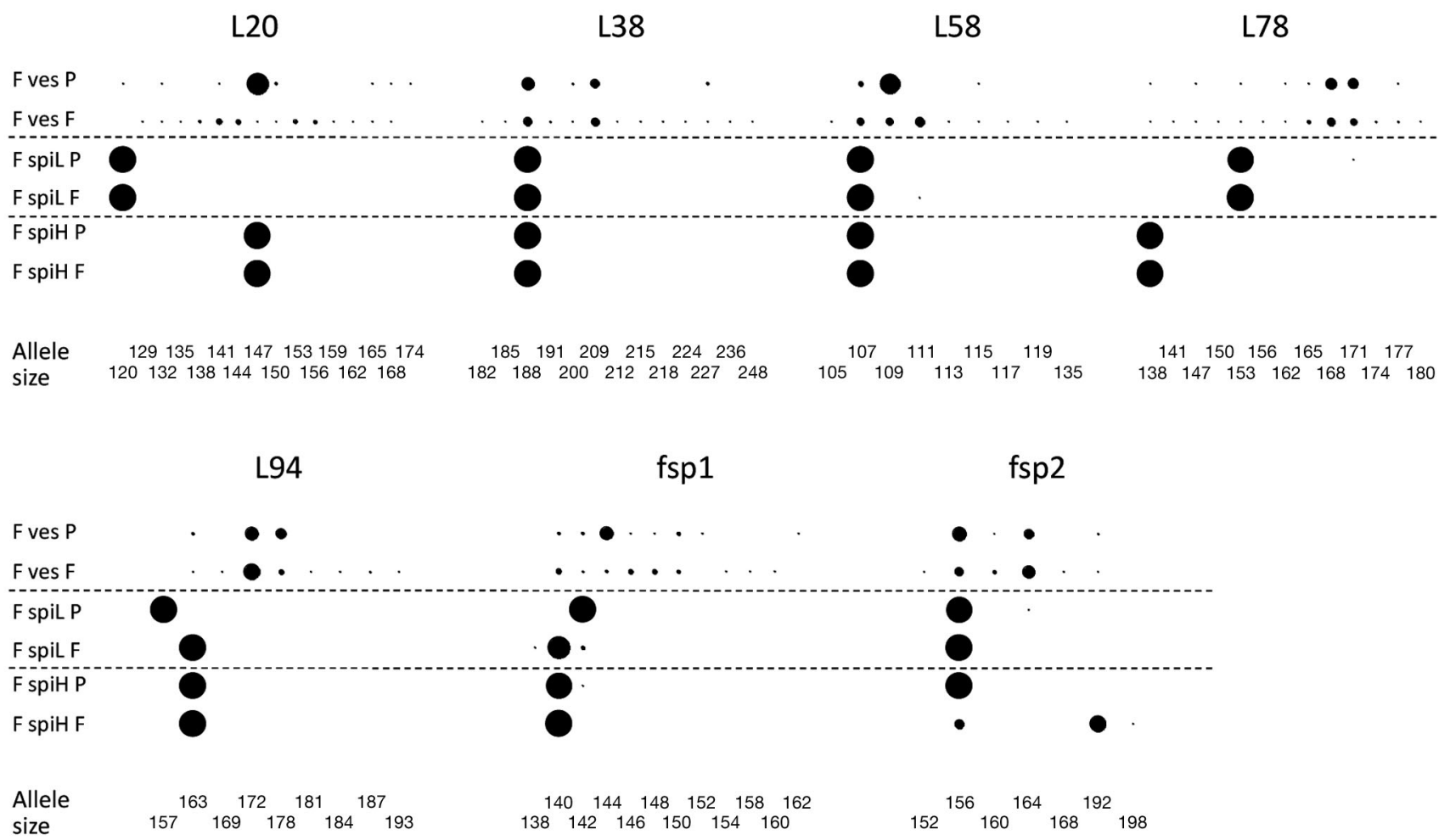

Fig. 3. Allele frequencies at 7 microsatellite loci calculated for each cluster in both regions. Numbers on the $x$-axis are allele sizes in base pairs for each locus. Each circle indicates presence of corresponding allele; diameter of circle represents frequency of that allele in the species. Fves $=$ Fucus vesiculosus; Fspi $=$ F. spiralis, $\mathrm{H}=$ High, L = Low, $\mathrm{P}=$ Portugal, $\mathrm{F}=$ France. Allele size notation corresponds to Perrin et al. (2007). Allelic frequencies table is provided in Supplement 1 at www.int-res.com/articles/suppl/ m405p163_app.pdf

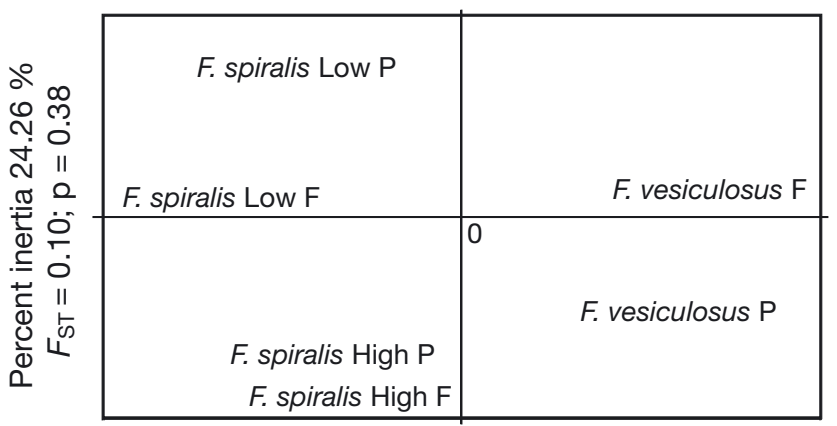

Percent inertia $55.77 \% F_{\mathrm{ST}}=0.22 ; \mathrm{p}=0.18$

Fig. 4. Principal component analysis (PCA) based on $7 \mathrm{mi}-$ crosatellite loci conducted with PCA-Gen software (Goudet 1999). Axis 1, separating Fucus vesiculosus from F. spiralis, represents $55.8 \%$ of total inertia, and Axis 2, separating F. spiralis-High and F. spiralis-Low, represents $24.3 \%$ of the total inertia. p values for $F_{S T}$ are given after 1000 randomizations

shore height reflect differences in selective pressures associated with emersion-dependent stress, for each cluster and each transect we computed the mean percentage of emersion time corresponding to the median altitude (Fig. 5). The results show that the differences in emersion time can explain the spatial segregation between $F$. vesiculosus and $F$. spiralis and differences between $F$. spiralis-Low and F. spiralis-High. Individuals of $F$. vesiculosus can spend up to $50 \%$ of their time out of water in Brittany but only $30 \%$ in Portugal. Individuals of $F$. spiralis-Low were emerged for at least $50 \%$ of the year, whereas those of $F$. spiralis-High were able to survive in areas exposed to air more than $60 \%$ of the year.

Finally, after definition of the 2 different genetic clusters F. spiralis-Low and F. spiralis-High, we noted in the field that individuals in the areas where these 2 genetic entities occur showed some morphological differences, allowing us to identify the F. spiralis-Low morphotype from the F. spiralis-High morphotype in the 2 geographic regions (Fig. 6). Although morphological phenotypic traits were not quantified for the sampled individuals, qualitative observations of the sampled individuals along the transect revealed that in general those that were later classified as F. spiralisHigh were generally smaller, bushy, with dichotomous ramifications, and bearing no rim around the receptacles, corresponding to the typical F. spiralis morphology and formerly described as the morphotype F. spiralis var typicus Böergesen, 1909. In contrast, 

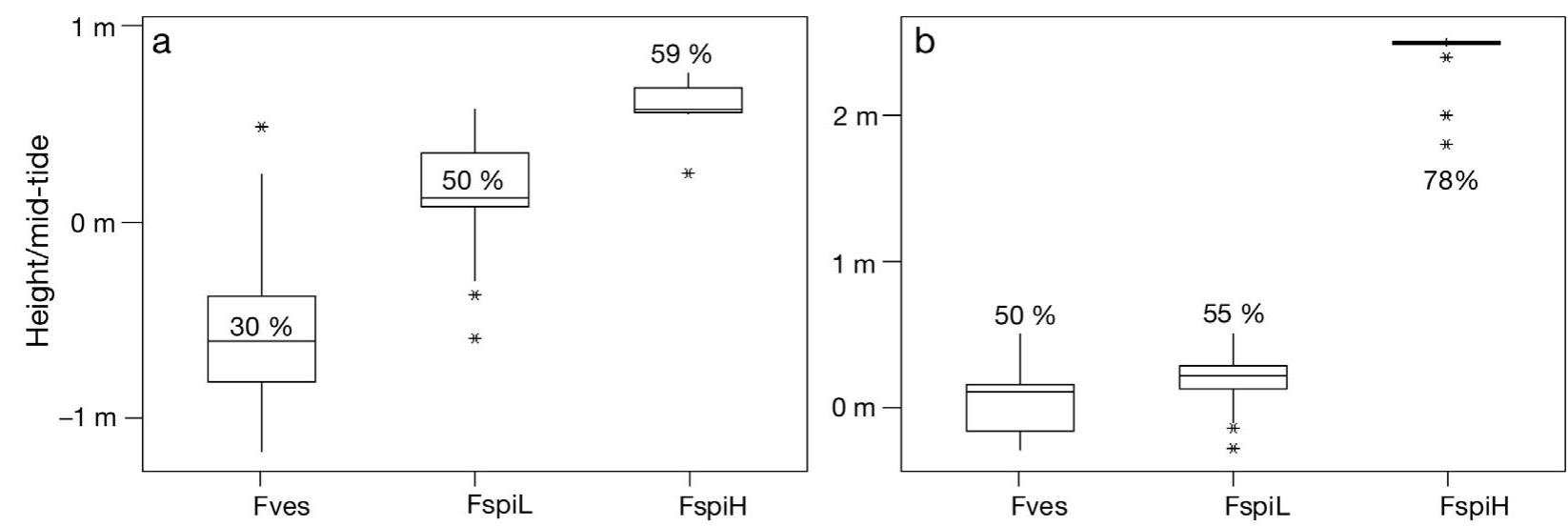

Fig. 5. Altitude of the different clusters in relation to the mid-tide point in (a) Viana do Castelo, Portugal and (b) Santec, France. Boxes represent interquartile ranges; internal horizontal bars represent the median; whiskers represent $1.5 \times$ the interquartile range and asterisks are given for outliers. Medians are $-0.61 \mathrm{~m}$ for Fucus vesiculosus (Fves), $0.13 \mathrm{~m}$ for F. spiralis-Low (FspiL), and $0.58 \mathrm{~m}$ for F. spiralis-High (FspiH) in Portugal, and they are respectively 0.10, 0.21, and $2.50 \mathrm{~m}$ in France. \%: mean percentage of time that the population spends emerged during the year

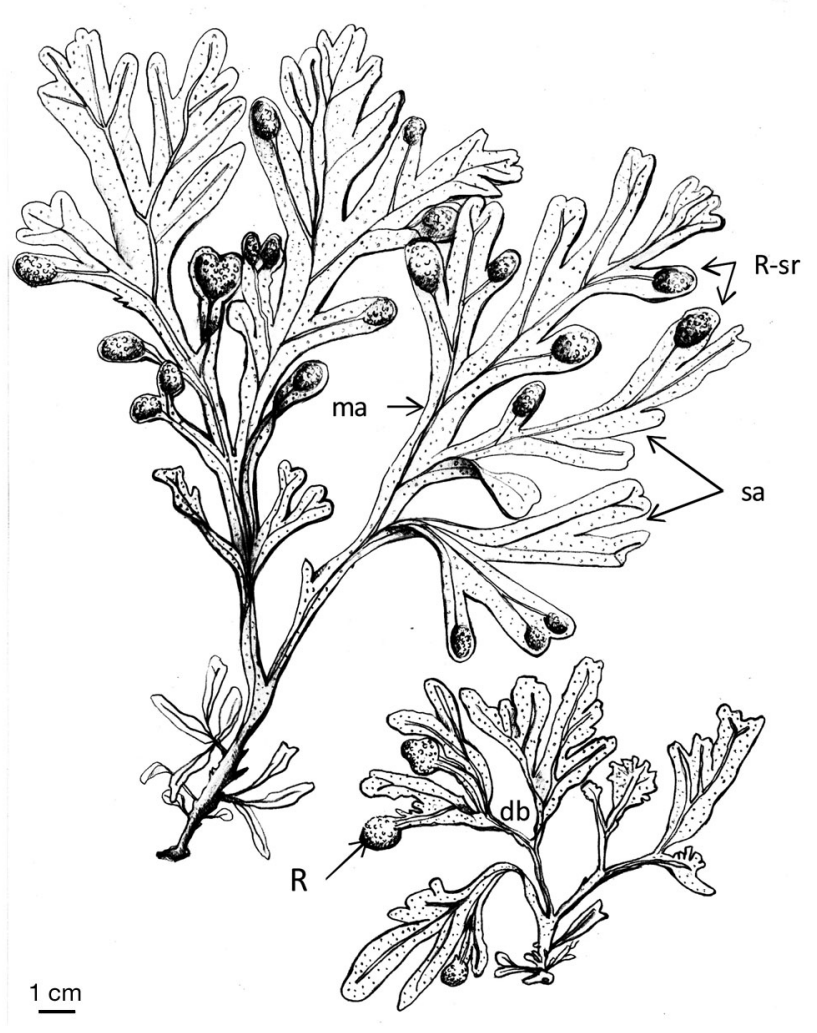

Fig. 6. The 2 morphotypes encountered in the sampling area in Santec, France. On the left Fucus spiralis-Low, which corresponds to the morphology of $F$. spiralis var. platycarpus; on the right F. spiralis-High, the typical F. spiralis morphology. R: receptacle without sterile rime; R-sr: receptacle with sterile rime; db: dichotomic branching; ma: main axis; sa: secondary axis. The same 2 morphotypes are encountered in Viana do Castelo
F. spiralis-Low genotypes were identified in areas where the existing morphotypes are longer and did not show a dichotomous branching pattern: each branch gives rise to one main thallus axis and one smaller side ramification. In addition, individuals generally exhibit large rims around the reproductive structures (receptacles). This morphology appears to correspond to the morphotype described as F. spiralis var. platycarpus Batters 1902.

\section{DISCUSSION}

By classifying geographically sympatric individuals exclusively using genetic markers, we recovered not only the previously known species but also novel entities within species. These different genetic entities cooccur on the same shores but are vertically distributed. From the lower to the higher part of the shore, a succession of 3 to 4 well-defined genetic clusters corresponding to Fucus serratus, F. vesiculosus, F. spiralisLow, and F. spiralis-High were present over $<100 \mathrm{~m}$. Even if the distribution of genotypes was well-correlated with the shore level, the distribution of these genetic entities was not totally disjunct, and genetic admixture was detected where individuals from the different entities occurred in sympatry. In some respects, the Fucus species complex could be interpreted as a succession of different ecological species along a vertical gradient of contrasting habitats. Such ecotype differences that are strongly correlated to different habitat type along the shore were extensively studied in Littorina saxatilis (see for critical review Butlin et al. 2008). In this marine gastropod, repeated 
experimental work has demonstrated that strong divergent natural selection acting across an environmental gradient is the mechanism that maintains ecotypic divergence in spite of ongoing gene flow (RolánAlvarez et al. 1997, Cruz et al. 2004a,b). However, demonstrating speciation with gene flow is far from easy due to the difficulty of separating the effects of time since divergence from gene flow (but see review of Nosil 2008). In this section, we discuss whether the shared genetic variation between the different Fucus clusters is simply a remnant of ancestral variation or if it is due to gene exchange after the populations started to separate.

It is now widely accepted that species in the Fucus genus experienced recent radiation (Leclerc et al. 1998, Serrão et al. 1999, Coyer et al. 2006). In recent studies, authors have tried to date these splitting events; by inferring a molecular clock, Hoarau et al. (2007) recently suggested a divergence time of 10 to 16 million yr between Fucus and Ascophyllum nodosum and of 2.3 to 5.5 million yr within Fucus and Muhlin \& Brawley (2009), using the same molecular clock, dated the divergence between haplotypes of $F$. vesiculosus between 35000 and 65000 yr ago, while with microsatellites, Pereyra et al. (2009) estimated the time since divergence of $F$. radicans and $F$. vesiculosus around $400 \mathrm{yr}$ ago (125 to 2475 yr ago) using a coalescent approach. As mentioned by Coyer et al. (2006) it is not trivial to find a consensus for the species concept within the Fucus genus because of intraspecific morphological variation and frequent hybridization among taxa. However, using nuclear (Serrão et al. 1999) or mtDNA (Coyer et al. 2006) phylogenies, these authors have defined 2 major lineages, the one including $F$. serratus being clearly divergent from the second containing the other 3 genetic entities recognized in this study (i.e. F. vesiculosus/F. spiralis). Thus, these 2 lineages result from an early divergence. As F. serratus is well-separated from the F. vesiculosus/F. spiralis complex, we suggest that although there may be some gene flow upon secondary contact, speciation was essentially allopatric. In contrast, previous phylogenies were unable to discriminate among F. spiralis and F. vesiculosus, and Coyer et al. (2006) proposed that $F$. spiralis might be still in the process of speciation. First, we will consider the dichotomy F. vesiculosus/F. spiralis and then we will discuss which factors may have lead to the separation of the 2 entities of F. spiralis.

\section{Divergence between Fucus vesiculosus and F. spiralis}

Contrary to previous phylogenies, recent population genetic analyses (Wallace et al. 2004, Billard et al. 2005, Engel et al. 2005) clearly support the separation of Fucus vesiculosus and F. spiralis into distinct genetic entities independent of geography. Despite our results that reveal $F$. spiralis to be composed of 2 genetically distinct entities, our analysis supports the previous interpretation since differentiation between $F$. vesiculosus and F. spiralis complex is higher than between $F$. spiralis-Low and F. spiralis-High. In contrast with previous studies, we analyzed individuals randomly sampled along vertical transects on the shore in order to obtain non-biased estimates of the degree of introgression between species. Even without the prior morphological choice of species, our results confirmed that the dioecious, vesicle-bearing $F$. vesiculosus forms a genetic cluster distinct from both hermaphroditic F. spiralis-Low and -High, with limited evidence for hybridization or ecological speciation. We suggest that, rather than parallel speciation, F. vesiculosus has originated just once and has spread throughout its range probably after the last glacial maximum (LGM) (Engel et al. 2005). The maintenance of the 2 species despite the external fertilization and their overlapping distribution on the shore might have been facilitated by selfing in $F$. spiralis but also by limited dispersal capacities and differential timing of gamete release in both species (Serrão et al. 1996, Ladah et al. 2008).

\section{Divergence between Fucus spiralis-Low and F. spiralis-High}

Within Fucus spiralis, different morphotypes were described in the early twentieth century: F. spiralis var platycarpus (Thuret) Batters 1902 and F. spiralis var typicus (Böergesen 1909) (see Hamel 1939), however these designations are rarely used in the current literature (but see Pérez-Ruzafa et al. 1993, Cairrão et al. 2004). Our study shows that at the genetic level, 2 clusters can be distinguished, corresponding to these early varietal designations, and that these occur at different heights on the shore. In marine macroalgae, and in particular in Fucus, the distinction of related species based on morphology is often problematic because of phenotypic variation, including intermediate phenotypes, which can lead to the misidentification of individuals (Coleman \& Muhlin 2008). In this context, the different morphotypes observed in F. spiralis could simply be due to phenotypic plasticity in relation to, for example, different levels of exposure to emersion stress. However, the genetic analysis of F. spiralis from Portugal and France showed that the different populations of $F$. spiralis clustered according to their morphotypes rather than their geographical vicinity, which supports genetic isolation rather than phenotypic plasticity.

Interestingly, the contrasting patterns exhibited by the different loci within Fucus spiralis suggest a history 
of divergence quite different from the history between $F$. vesiculosus and F. spiralis complex. Specifically, 3 kinds of response were observed: (1) L38 and L58 are fixed or nearly fixed for one allele in the entire F. spiralis complex; (2) In contrast, L20 and L78 discriminates between the $2 \mathrm{~F}$. spiralis-Low and F. spiralisHigh clusters, since they are fixed for different alleles; (3) Finally, 3 loci (L94, fsp1, and fsp2) reveal regional divergence either within F. spiralis-Low (at L94 and fsp1) or within F. spiralis-High (at fsp2), suggesting geographical differentiation within clusters. This discordant pattern between different loci could correspond to the effect of genetic drift on neutral loci, which is surely facilitated in these 2 entities by the high level of selfing leading to the rapid fixation of alleles. Given the clearly different emersion times the 2 clusters have to face (50 to $55 \%$ for F. spiralis-Low vs. 59 to $78 \%$ for $F$. spiralis-High) a possible scenario for the existence of the 2 clusters $F$. spiralis-High and F. spiralis-Low would be that, like for Littorina saxatilis (Quesada et al. 2007), parallel evolution of similar morphotypes inhabiting an equivalent area of the shore is occurring in the different regions, driven by ecological selective pressures, for example desiccation stress. As for $F$. radicans and $F$. vesiculosus, for which clonality may have acted as an isolating system and led to a rapid speciation in a marginal environment such as the Baltic Sea (Pereyra et al. 2009), in the case of F. spiralis, reproductive isolation between morphotypes may be reinforced primarily by selfing, preventing gene flow between F. spiralis entities on the one hand and accelerating the fixation of mutations on the other (Wright et al. 2008).

Based on our results, 2 different scenarios seem to be involved in the evolution of the 3 clusters, Fucus vesiculosus, F. spiralis-Low, and F. spiralis-High. First, only one speciation event seems to have occurred, in allo-, para-, or sympatry cannot be known. Reproductive isolation, even if not complete, may have been maintained by aspects of reproductive ecology (for example, timing of gamete release) that limit interspecific gamete encounters. Second, parallel evolution of 2 'morphotypes' driven by natural selection and facilitated by a high selfing rate seems to be ongoing in at least these 2 geographically distant regions of Portugal and France. Additional studies focusing on the case of $F$. spiralis are thus urgently required to confirm or reject this scenario. Whatever the case, much may be learned from a re-examination of the older literature in which the typical $F$. spiralis morphotype was distinguished from the morphologically distinct $F$. spiralis var platycarpus (Thuret) Batters 1902, which is shown here to correspond to a distinct genetic entity. In conclusion, the genus Fucus is a model of ancestral and ongoing evolutionary divergence at various levels and at different time scales. It originally diverged into 2 clades (Coyer et al. 2006, Serrão et al 1999), one including taxa that are more tolerant to emersion stresses (including F. spiralis and F. vesiculosus) and another composed of taxa that have low tolerance to emersion. Later, within the 'stress tolerant' clade, a hermaphroditic vs. dioecious divergence in reproductive mode might have helped reinforce the divergence between the co-occurring species $F$. spiralis and $F$. vesiculosus, where the former, a selfing hermaphrodite, may be more able to maintain locally adaptative traits to life on the high shore. In the present study, we have discovered that at a yet more recent time scale, within a selfing $F$ spiralis complex, divergence between 2 genetic entities occurred, with spatial segregation along the intertidal zone suggesting that differences in selective traits might have contributed to their divergence.

Acknowledgements. This research was supported by a doctoral grant from FCT, Portugal, and European Social Fund to E.B. Additional supports from the Networks of Excellence 'Marine Genomics' (Algal Node) and 'MarBef' (GBirm), and from the 'ARCUS' program of the French Ministry of Foreign Affairs and FCT programs co-funded by FEDER. Thanks to S. Arnaud-Haond and J. Hollander for their comments on earlier versions of the manuscript, to J. M. Neiva and to all people having helped in the field: M. Billard, C. Broudin, C. R. Engel, B. Faure, S. Le Cam, D. Muths, S. Plouviez, F. Rigal, D. Roze, G. Schaal, and M. Voisin. Special thanks to V. Valéro for the help in the drawing of the $2 F$. spiralis entities.

\section{LITERATURE CITED}

Alberto F (2009) MsatAllele_1.0: an R package to visualize the binning of microsatellite alleles. J Hered 100:394-397

Belkhir K, Borsa P, Chikhi L, Raufaste N, Bonhomme F (2004) GENETIX 4.05, logiciel sous Windows TM pour la génétique des populations. Laboratoire Génome, Populations, Interactions, CNRS UMR 5000, Université de Montpellier II, Montpellier, France

Billard E, Serrão EA, Pearson GA, Engel CR, Destombe C, Valero M (2005) Analysis of sexual phenotype and prezygotic fertility in natural populations of Fucus spiralis, F. vesiculosus (Fucaceae, Phaeophyceae) and their putative hybrids. Eur J Phycol 40:397-407

Butlin RK, Galindo J, Grahame JW (2008) Sympatric, parapatric or allopatric: the most important way to classify speciation? Phil Trans R Soc B 363:2997-3007

Cairrão E, Couderchet M, Soares AMVM, Guilhermino L (2004) Glutathione-S-transferase activity of Fucus spp. as a biomarker of environmental contamination. Aquat Toxicol 70:277-286

Chapman ARO (1990) Competitive interactions between Fucus spiralis L and Fucus vesiculosus L (Fucales, Phaeophyta). Hydrobiologia 204:205-209

Chapman ARO (1995) Functional ecology of fucoid algae23 years of progress. Phycologia 34:1-32

> Chapman ARO, Johnson CR (1990) Disturbance and organization of macroalgal assemblages in the northwest Atlantic. Hydrobiologia 192:77-121

Coleman MA, Brawley SH (2005) Spatial and temporal vari- 
ability in dispersal and population genetic structure of a rockpool alga. Mar Ecol Prog Ser 300:63-77

Coleman MA, Muhlin JF (2008) Patterns of spatial variability in the morphology of sympatric fucoids. Northeast Nat 15:111-122

> Connell JH (1972) Community interactions on marine rocky intertidal shores. Annu Rev Ecol Syst 3:169-192

Coyer JA, Peters AF, Hoarau G, Stam WT, Olsen JL (2002) Hybridization of the marine seaweeds, Fucus serratus and Fucus evanescens (Heterokontophyta: Phaeophyceae) in a 100 -year-old zone of secondary contact. Proc Biol Sci 269:1829-1834

Coyer JA, Hoarau G, Oudot-Le Secq MP, Stam WT, Olsen JL (2006) A mtDNA-based phylogeny of the brown algal genus Fucus (Heterokontophyta; Phaeophyta). Mol Phylogenet Evol 39:209-222

Coyer JA, Hoarau G, Stam WT, Olsen JL (2007) Hybridization and introgression in a mixed population of the intertidal seaweeds Fucus evanescens and F. serratus. J Evol Biol 20:2322-2333

> Cruz R, Carballo M, Conde-Padín P, Rolán-Alvarez E (2004a) Testing alternative models for sexual isolation in natural populations of Littorina saxatilis: Indirect support for byproduct ecological speciation? J Evol Biol 17:288-293

> Cruz R, Vilas C, Mosquera J, García C (2004b) Relative contribution of dispersal and natural selection to the maintenance of a hybrid zone in Littorina. Evolution 58: 2734-2746

> David P, Pujol B, Viard F, Castella V, Goudet J (2007) Reliable selfing rate estimates from imperfect population genetic data. Mol Ecol 16:2474-2487

> Davison IR, Pearson GA (1996) Stress tolerance in intertidal seaweeds. J Phycol 32:197-211

> Dring MJ, Brown FA (1982) Photosynthesis of intertidal brown algae during and after periods of emersion: a renewed search for physiological causes of zonation. Mar Ecol Prog Ser 8:301-308

Engel CR, Brawley SH, Edwards KJ, Serrão E (2003) Isolation and cross-species amplification of microsatellite loci from the fucoid seaweeds Fucus vesiculosus, Fucus serratus and Ascophyllum nodosum (Heterokontophyta, Fucaceae). Mol Ecol Notes 3:180-182

Engel CR, Daguin C, Serrão EA (2005) Genetic entities and mating system in hermaphroditic Fucus spiralis and its close dioecious relative F. vesiculosus (Fucaceae, Phaeophyceae). Mol Ecol 14:2033-2046

Fitzpatrick BM, Fordyce JA, Gavrilets S (2008) What, if anything, is sympatric speciation? J Evol Biol 21:1452-1459

Galindo J, Moran P, Rolan-Alvarez E (2009) Comparing geographical genetic differentiation between candidate and noncandidate loci for adaptation strengthens support for parallel ecological divergence in the marine snail Littorina saxatilis. Mol Ecol 18:919-930

Gao H, Williamson S, Bustamante CD (2007) A Markov chain Monte Carlo approach for joint inference of population structure and inbreeding rates from multilocus genotype data. Genetics 176:1635-1651

Gomez-Garreta A (2000) Flora Phycologica Iberica, Vol 1. Fucales. Servicio de Publicaciones, Universidad de Murcia, Spain

Goudet J (1995) FSTAT (version 12): a computer program to calculate F-statistics. J Hered 86:485-486

Goudet J (1999) PCA-GEN for Windows (version 1.2, August 1999), computer package for Windows which performs principal component analysis on gene frequency data. www2.unil.ch/popgen/softwares/

Guiry MD, Guiry GM (2009) AlgaeBase world-wide elec- tronic publication. National University of Ireland, Galway. www.algaebase.org

Hamel G (1939) Phéophycées de France. Wolf, Rouen

Hawkins SJ, Hartnoll RG (1985) Factors determining the upper limits of intertidal canopy-forming algae. Mar Ecol Prog Ser 20:265-271

> Hey J (2006) Recent advances in assessing gene flow between diverging populations and species. Curr Opin Genet Dev 16:592-596

Hoarau G, Coyer JA, Veldsink JH, Stam WT, Olsen JL (2007) Glacial refugia and recolonization pathways in the brown seaweed Fucus serratus. Mol Ecol 16:3606-3616

Jonsson PR, Granhag L, Moschella PS, Aberg P, Hawkins SJ, Thompson RC (2006) Interactions between wave action and grazing control the distribution of intertidal macroalgae. Ecology 87:1169-1178

Kniep H (1925) Ueber Fucus-Bastard. Flora 118/119:331-338

Ladah LB, Feddersen F, Pearson GA, Serrão EA (2008) Egg release and settlement patterns of dioecious and hermaphroditic fucoid algae during the tidal cycle. Mar Biol 155:583-591

Leclerc MC, Barriel V, Lecointre G, De Reviers B (1998) Low divergence in rDNA ITS sequences among five species of Fucus (Phaeophyceae) suggests a very recent radiation. J Mol Evol 46:115-120

Lubchenco J (1980) Algal zonation in the New England rocky intertidal community: an experimental analysis. Ecology 61:333-344

Muhlin JF, Brawley SH (2009) Recent versus relic: discerning the genetic signature of Fucus vesiculosus (Heterokonphyta; Phaeophyceae) in the northwestern Atlantic. J Phycol 45:828-837

Nosil P (2008) Speciation with gene flow could be common. Mol Ecol 17:2103-2106

Pearson GA, Kautsky L, Serrão EA (2000) Recent evolution in Baltic Fucus vesiculosus: reduced tolerance to emersion stresses compared to intertidal (North Sea) populations. Mar Ecol Prog Ser 202:67-79

> Pearson GA, Lago-Leston A, Mota C (2009) Frayed at the edges: selective pressure and adaptive response to abiotic stressors are mismatched in low diversity edge populations. J Ecol 97:450-462

Pereyra R, Bergström L, Kautsky L, Johannesson K (2009) Rapid speciation in a newly opened postglacial marine environment, the Baltic Sea. BMC Evol Biol 9:70

> Pérez-Ruzafa I, Gallardo T, Gómez-Cancio R (1993) Numerical taxonomy of some taxa of the genus Fucus in the Iberian Peninsula. Hydrobiologia 260/261:81-90

Perrin C, Daguin C, Van De Vliet M, Engel CR, Pearson GA, Serrão EA (2007) Implications of mating system for genetic diversity of sister algal species: Fucus spiralis and Fucus vesiculosus (Heterokontophyta, Phaeophyceae). Eur J Phycol 42:219-230

Pritchard JK, Stephens M, Donnelly P (2000) Inference of population structure using multilocus genotype data. Genetics 155:945-959

> Quesada H, Posada D, Caballero A, Moran P, Rolan-Alvarez E (2007) Phylogenetic evidence for multiple sympatric ecological diversification in a marine snail. Evolution 61: 1600-1612

Rolán-Alvarez E, Johannesson K, Erlandsson J (1997) The maintenance of a cline in the marine snail Littorina saxatilis: the role of home site advantage and hybrid fitness. Evolution 51:1838-1847

Schluter D (2001) Ecology and the origin of species. Trends Ecol Evol 16:372-380

Schluter D (2009) Evidence for ecological speciation and its 
alternative. Science 323:737-741

Serrão E, Pearson G, Kautsky L, Brawley SH (1996) Successful external fertilization in turbulent environments. Proc Natl Acad Sci USA 93:5286-5290

Serrão E, Alice LA, Brawley SH (1999) Evolution of the Fucacae (Phaeophyceae) inferred from nrDNA-ITS. J Phycol 35:382-394

Skene KR (2004) Key differences in photosynthetic characteristics of nine species of intertidal macroalgae are related to their position on the shore. Can J Bot 82:177-184

Stomps TJ (1911) Etudes topographiques sur la variabilité des Fucus vesiculosus L. platycarpus Thur et ceranoides L. Rec Inst Bot Léo Errera Bruxelles 8: 326-377

Takebayashi N, Morrell PL (2001) Is self-fertilization an evolutionary dead end? Revisiting an old hypothesis with genetic theories and a macroevolutionary approach. Am J Bot 88:1143-1150

Underwood AJ (1979) The ecology of intertidal gastropods. Adv Mar Biol 16:111-210

Editorial responsibility: Philippe Borsa, Montpellier, France
Van Oosterhout C, Hutchinson WF, Wills DPM, Shipley P (2004) MICRO-CHECKER: software for identifying and correcting genotyping errors in microsatellite data. Mol Ecol Notes 4:535-538

- Van Oosterhout C, Weetman D, Hutchinson WF (2006) Estimation and adjustment of microsatellite null alleles in nonequilibrium populations. Mol Ecol Notes 6:255-256

Vernet P, Harper JL (1980) The costs of sex in seaweeds. Biol J Linn Soc 13:129-138

Wallace AR, Klein AS, Mathieson AC (2004) Determining the affinities of salt marsh fucoids using microsatellite markers: evidence of hybridization and introgression between two species of Fucus (Phaeophyceae) in a Maine estuary. J Phycol 40:1013-1027

Weir BS, Cockerham CC (1984) Estimating F-statistics for the analysis of population structure. Evolution 38:1358-1370

Wright SI, Ness RW, Foxe JP, Barrett SCH (2008) Genomic consequences of outcrossing and selfing in plants. Int $\mathrm{J}$ Plant Sci 169:105-118

Submitted: May 11, 2009; Accepted: January 26, 2010

Proofs received from author(s): April 23, 2010 